\title{
A Review of EFL Formulaic Language Acquisition and Teaching intervention
}

\author{
Chuanfu Chen ${ }^{1}$, Songsong Chen ${ }^{2}$ \\ ${ }^{1}$ Postgraduate Student, Yangtze University, China \\ ${ }^{2}$ Associate Professor, Yangtze University, China
}

Received: 05 Aug 2021; Received in revised form: 10 Sep 2021; Accepted: 15 Sep 2021

(C)2021 The Author(s). Published by TheShillonga. This is an open access article under the CC BY license

(https://creativecommons.org/licenses/by/4.0/)

\begin{abstract}
This paper reviews EFL formulaic language research in international and Chinese domestic academia from the perspectives of language acquisition and language teaching. Current studies have some limitations due to different types of reasons. For example, a lack of representativeness in the selection of target items, a lack of attention to learner's differences, and a scanty of high-quality EFL formulaic sequences instruction research. Future research can pay more attention to learners' differences that may affect the acquisition and learning process of the formulaic language, with the aim of exploring effective methods and approaches to improve the competence of EFL learners and promoting the optimization of theories exploring the teaching of EFL formulaic language.
\end{abstract}

Keywords - formulaic language; acquisition; incidental acquisition; teaching intervention.

\section{INTRODUCTION}

Formulaic language is a kind of multi-word unit that has features of both vocabulary and grammar. It is a complex of form and meaning, which includes idioms, collocations, lexical bundles, recurring word clusters, frame phrases and so on (Wray 2000). Learners' formulaic language knowledge is an important embodiment of their mastery of grammatical knowledge, semantic relation and pragmatic function. For EFL learners, the knowledge of formulaic language can not only help them understand the target language more accurately, but also make them more fluent in the output language. In the field of second language acquisition (SLA), formulaic language has become an important indicator to measure the development of learners' language ability (wary 2002; Ellis et al. 2008; Ma Rong 2020). To date, the number of theoretical and empirical studies on formulaic language acquisition and teaching intervention has been increasing and researches have yielded fruitful results. This paper aims to sort out and comment on the important research results related to formulaic language from the two dimensions: $E F L$ formulaic language acquisition and the impact of EFL formulaic language teaching intervention, hopefully to provide some reference for follow-up research.

\section{EFL FORMULAIC LANGUAGE ACQUISITION}

Based on Krashen's distinction between learning and acquisition, EFL formulaic language acquisition here refers to the direct learning of second language formulaic language autonomously with corpus-based reference materials or textbooks or dictionaries (Zhang Qun 2020). Scholars have made theoretical discussions on corpus-based formulaic language learning and the effectiveness of the method is empirically studied. In the application of corpus as a tool for direct formulaic language learning, learners conduct autonomous learning through tool retrieval. Bao Gui (2006) did a theoretical exploration 
by introducing the Collins online English Corpus (Cobuild) retrieval tool. By comparing formulaic language in English and Chinese corpora, he aimed to help Chinese English learners to analyze the semantic scope of formulaic language independently with the online corpus and enrich the content of vocabulary learning in today's China. Fang Di (2008) made an empirical study and guided learners to use the formulaic language information provided in the online corpus to help learners to use the formulaic sequences provided in the corpus-assisted teaching textbook consciously in their writing. The real-time post-test found that the effect of direct learning of formulaic sequences in the autonomous learning group was not very obvious. However, the delayed post-test showed that the corpus-based independent learning process of formulaic sequences improved the subjects' ability to recognize them and increased their awareness of learning them in the daily life. Chen (2011) proved that the web-based formulaic language retrieval tool can play a positive role in the subjects' second language formulaic language acquisition by comparing the completion of the subjects' limited time translation task, and the subjects generally recognized this method. Daskalovska (2015) also proved through empirical research that corpus-based formulaic language self-guided learning method can better improve students' language ability than traditional vocabulary learning methods. It can be seen that the tool retrieval based formulaic language learning method can help second language learners better acquire and use formulaic language.

\section{EFL FORMULAIC LANGUAGE TEACHING INTERVENTION}

The existing intervention research on EFL formulaic language teaching focuses on incidental acquisition and intentional instruction. Incidental acquisition of EFL formulaic language is relative to second language intentional learning. Incidental acquisition refers to that when students complete other tasks (such as reading or communication), their attention is not on the memory of words, but inadvertently acquire words (Laufer 1998, Schmitt 2010) while intentional EFL formulaic language instruction refers to the use of explicit teaching methods to teach the target formulaic sequences, or explicitly require learners to recite the target formulaic language and inform them that they need to be tested.

\section{The incidental learning of EFL formulaic sequences}

Previous studies have aimed to explore effective teaching methods and learning conditions to promote second language learners' incidental acquisition of formulaic language. First of all, as an important influencing factor, frequency is still tested. For example, Webb (2013) proved through experiments that the mode of learning revised graded reading materials in the listening reading interaction mode can help learners complete the incidental acquisition of formulaic language knowledge, and the effect of formulaic language acquisition is more significant when the target formulaic language is repeated many times. Zhou Dandan (2014) used empirical research to investigate the impact of contact frequency types on senior high school students' formulaic language acquisition. She found that frequency has a significant impact on formulaic sequences acquisition: different frequency types have different acquisition effects, and the effect of skewed distribution is better than that of normal distribution.

In the discussion of the impact of teaching methods on incidental acquisition, Laufer \& girsai (2008) adopted two teaching methods to conduct an experiment on formulaic language teaching for senior high school students. It was found that compared with the meaning centered and form centered teaching methods, the post task contrastive form focused teaching method can promote the EFL formulaic language incidental acquisition to have a positive impact. In addition, due to the importance of frequency in the study of formulaic language in corpus, many scholars (such as Chan \& Liou, 2005; Daskalovska 2014; Boulton \& Cobb 2016; Cobb 2018) explored and demonstrated the data-driven formulaic language teaching method. As an important part of the study of formulaic language, Lu Xiaofei and Liu Yingying (2019) summarized the study of formulaic language in academic English researches based on corpus, and expounded the importance and feasibility of the combination of formal analysis and functional analysis in further academic English research and teaching.

In terms of output task types, Huang Yan (2016) 
investigated the effects of four different types of output tasks (writing, reconstruction, re-translation and retelling reinforcement) on adult EFL learners' attention to formulaic language and incidental acquisition in subsequent related inputs through multi-variable empirical research. She proved that focused output tasks can improve learners' attention to formulaic language. And the higher the focus of the output task, the deeper the attention processing triggered, and the better the acquisition effect and persistence.

As for learner differences, Golaghaei (2011) conducted a vocabulary test on learners of two cognitive styles and found that at the same level, field independent cognitive style learners scored higher in understanding and productive vocabulary knowledge than field dependent cognitive style learners. Zhang Jing (2018) also confirmed that field independent cognitive style has more advantages than field dependent cognitive style in the process of formulaic language acquisition. And She found that the higher the prominence of learning materials, the more it can stimulate learners' attention, the better the immediate acquisition effect and its delayed maintenance.

In terms of learners' previous vocabulary knowledge, Peter \& Webb's (2018) study found that in the case of audio-visual input, the subjects' previous vocabulary was positively correlated with the incidental acquisition effect of formulaic language in the tasks of form recognition and meaning recall. Puimège \& Peters (2019) even found that second language learners can incidentally acquire formulaic language in only one audio-visual input without subtitles. In the formal recall task, it was further confirmed that the subject's vocabulary size was positively correlated with the acquisition effect, and that the learner's previous vocabulary might promote the acquisition of formulaic sequences.

Previous studies have shown that the effect of incidental acquisition of EFL formulaic language is affected by many factors, such as learning materials and types, learning mode, number of words in the formulaic sequence, task types and test time. Most studies distinguished learners' English proficiency and age (such as Huang Yan 2016, puimège \& Peters 2019), but few have focused on learners' own factors like learning attitude and cognitive style. There are fewer studies on the impact of language aptitude and working memory on incidental acquisition of formulaic sequences and need to be further deepened ( $\mathrm{Qu}$ dianning, Peng Jinding, 2016).

\section{The intentional instruction of EFL formulaic language}

A rather consistent finding that the formulaic language teaching model can better improve learners ability than the traditional teaching method was made by previous studies on the intentional instruction of EFL formulaic language. In terms of teaching methods, Yu Xiulian (2008) found through a two-year formulaic language teaching experiment that the amount of formulaic language has a greater impact on students' English application ability than the amount of words, and this teaching method is more conducive to improving college students' English application ability than traditional vocabulary teaching method. Wu Ping (2014) focused on the effectiveness of the task driven formulaic language teaching model. The experimental results show that the listening, reading, writing and translation ability of the experimental class is significantly different from that of the control class using the traditional teaching method, and the relevant questionnaire survey also showed that this model helps to cultivate students' language internalization ability, enhance their learning initiative and reduce their dependence on teachers. However, more precise experiments are needed to demonstrate which one is at work: the task-driven method or the formulaic language teaching model? What's further, Shi luoxiang (2014) believed that vocabulary teaching should be turned into an overall teaching centered on formulaic language teaching, and suggested that formulaic language teaching and its strategies should be incorporated into the syllabus of the primary and secondary schools.

In the aspect of recitation of formulaic language, foreign scholars with English as the target language pay more attention to their phonetic features. Some scholars have found that compared with non-alliterative formulaic language, formulaic sequences with alliterative characteristics (such as cut corners; slippery slope; time will tell; toss and turn; good as gold; life-long learning; better safe than sorry, time and tide wait for no man) shows a certain degree of acquisition advantage in the test, and the 
recall test effect is significantly enhanced after the teacher emphasizes the alliteration feature of the target formulaic language (Boers, Lindstromberg \& Eyckmans 2014; Eyckmans, Boers, \& Lindstromberg 2016; Lindstromberg \& Boers, 2008). In addition, these researchers also found that the formulaic language of vowel rhyme(such as small talk; cook the books; hit and miss) and formulaic sequences with the same rhyme(such as steel clear; brain drain; left high and dry) also has a similar test effect(Boers et al., 2014; Lindstromberg \& Boers, 2008). They further argued that if these characteristics are pointed out in relevant textbooks or teaching process, it will help learners' memory of the target formulaic language.

By contrast, the influence of recitation on the production of formulaic language in subsequent compositions or oral tests is mostly investigated in China. Deng Liming and Wang Xiangyun (2007) focused on the correlation between recitation input and writing proficiency and discussed the effect of recitation language input on the development of Chinese students' second language writing ability. The research shows that recitation language input is obviously helpful to the acquisition and consolidation of Chinese students' writing output. Zhao Jizheng (2008) focused on the impact of recitation on English formulaic language learning, the subjects are required to recite 10 short passages with an average word length of 120 words within two weeks, and clearly informed the subjects that they would be tested. The results show that recitation can improve the accuracy of formulaic sequences to a certain extent, but the learning effects of different types of formulaic sequences are different in composition output. The reason may be that the subjects failed to pay enough attention to the target formulaic sequences when reciting the passage, and the teaching intervention time was short, and some target formulaic sequences failed to become productive in-depth knowledge which was saved in the long term memory. Qi Yan and Xia Jun (2016) investigated the impact and degree of reciting formula language on Chinese English learners' composition and oral output. After eight weeks of teaching, they found that formula language recitation can effectively promote the development of learners' writing and oral ability in terms of fluency and accuracy, and simultaneously the reciting of formulaic language plays a more obvious role in improving oral ability than writing. In short, studies have shown that recitation has a positive impact on the acquisition of formulaic sequences, notwithstanding the effect is affected by the factors of target formulaic language themselves.

Due to the way of task setting, it may be difficult for researchers to really distinguish incidental learning from intentional learning in practice, so the research scope is rather narrow to some degree, and there are few diachronic studies and case studies. However, the existing research has had a positive impact on formulaic sequences teaching in China based on different teaching objectives.

\section{CONCLUSION AND PROSPECT}

Scholars at home and abroad have made useful attempts to explore the optimal method of EFL formulaic language acquisition and teaching, but there are some limitations in the current researches. Firstly, there are still disputes about the definition of formulaic language. There are many overlaps in formulaic language, collocation, lexical chunks, lexical bundles, prefabricated lexical chunks, idioms, word clusters and other terms, which need to be further clarified (Gao Hang 2017; Zhang Qun (2020). Secondly, there are few studies on the combination of multiple teaching methods and the impact of different situational factors on formulaic sequences teaching, and there is no exploration on whether some teaching methods that have attracted much attention (such as explicit teaching method, post task comparative form focus teaching method, etc.) are also applicable to different types of formulaic language (Ma Rong 2020). Thirdly, there are few existing studies on learners' own factors. How learners' previous vocabulary knowledge and other factors affect the acquisition effect of formulaic language needs to be further verified. In addition, because the research on formulaic language teaching has not yet formed a complete theoretical system and experimental paradigm, the scientificity and popularization of its conclusion need to be further demonstrated (Zhang Qun 2020). 


\section{REFERENCES}

[1] Boers, F., Lindstromberg, S., \& Eyckmans, J. Is alliteration mnemonic without awareness-raising $[\mathrm{J}]$ ? Language Awareness, 2014, 23(4):291-303.

[2] Boers, F., Lindstromberg, S., \& Eyckmans, J. When does assonance make EFL lexical phrases memorable [J]? The European Journal of Applied Linguistics and TEFL, 2014, 3(1), 93-107.

[3] Boulton, A., \& Cobb, T. Corpus use in language learning: A meta-analysis [J]. Language Learning, 2016, 65(2):1-46.

[4] Chan, T. P. \& Liou, H.C. Effects of web-based concordance instruction on EFL students' learning of verb-noun collocations. Computer Assisted Language Learning, 18(3), 231-251.

[5] Chen, H. Developing and evaluating and web-based collocation retrieval tool for EFL students and teachers $[\mathrm{J}]$. Computer Assisted Language Learning, 2011, 24(1): 59-76.

[6] Cobb T. From corpus to CALL: The use of technology in teaching and learning formulaic language $[\mathrm{M}] / /$ Understanding formulaic language. Routledge, 2018:192-210.

[7] Daskalovska, N. Corpus-based versus traditional learning: A meta-analysis [J]. Computer Assisted Language Learning, 2014, 28(2): 130-144.

[8] Daskalovska,N. Corpus-based versus traditional learning of collocations[J]. Computer Assisted Language Learning ,2015, 28(2): 130-144.

[9] Ellis N C, Simpson Vlach R \& Maynard C. Formulaic language in native and second language speakers: Psycholinguistics, corpus linguistics, and TESOL. TESOL Quarterly, 2008, 42(3):375-396.

[10] Eyckmans, J., Boers, F., \& Lindstromberg, S. The impact of imposing processing strategies on EFL learners' deliberate study of lexical phrases [J]. System, 2016, 56(3), 127139.

[11] Golaghaei, N. Vocabulary breath and field dependence/independence cognitive style [J]. Advances in Language and Literary Studies, 2011(2):156-170.

[12] Laufer B. The development of passive and active vocabulary in a second language: Same or different? [J]. Applied linguistics, 1998, 19(2): 255-271.

[13] Laufer,B. \& Girsai. Form-focused instruction in second language vocabulary learning: A case for contrastive analysis and translation [J]. Applied Linguistics, 2008, 29(4): 694-716.

[14] Lindstromberg, S., \& Boers, F. Phonemic repetition and the learning of lexical chunks: The mnemonic power of assonance [J]. System, 2008,36(3), 423-436.

[15] Lindstromberg, S., \& Boers, F. The mnemonic effect of noticing alliteration in lexical chunks [J]. Applied Linguistics, 2018, 29(2), 200-222.

[16] Peters, E. and S. Webb. Incidental vocabulary acquisition through viewing EFL television and factors that affect learning [J]. Studies in Second Language Acquisition, 2018, 40(01): 551-577.

[17] Puimège, E., \& Peters, E. Learning EFL vocabulary from audiovisual input: an exploratory study into incidental learning of single words and formulaic sequences $[\mathrm{J}]$. The Language Learning Journal, 2019, 47(04):424-438.

[18] Szudarski. Effects of meaning-and-form-focused instruction on the acquisition of verb+noun collocations in EFL English [J]. Journal of Second Language Teaching and Research, 2012, 1(2): 30-37.

[19] Wary A. Formulaic Language and the Lexicon [M]. Cambridge: Cambridge University Press, 2002.

[20] Wary A. Formulaic sequences in second language teaching: Principle and Practice [J]. Applied Linguistics, 2000, 21(4):463-489.

[21] Bao. The pedagogical use of online Cobuild concordance and collection sampler [J]. Computer-assisted Foreign Language Education, 2006(06):63-69.

[22] Deng \& Wang. A study of efficacy of recitation input for the development of Chinese tertiary-level students' EFL writing proficiency $[\mathrm{J}]$. Foreign Language Education, 2007(04):52-56.

[23] Fang. An empirical study on the corpus-based verb-noun collocation instruction [J]. Computer-assisted Foreign Language Education, 2008(06):22-27.

[24] Gao. The role of chunks in second language acquisition from the perspective of Construction Grammar [J]. Journal of PLA University of Foreign Languages, 2017, 40(02):86-94.

[25] Huang. The effect of output task-types on the incidental acquisition of EFL formulaic sequences [J]. Foreign Language Teaching and Research, 2016, 
48(01):74-86+160-161.

[26] Lu \& Liu. Corpus-based research on formulaic language in academic English and its pedagogical applications [J]. Foreign Language World, 2019(05):30-38.

[27] Ma. The effectiveness of formulaic language teaching intervention: A meta-analysis [J]. Foreign Language World, 2020(03):80-88.

[28] Qi \& Xia. The effect of chunk recitation on English writing and speaking proficiency [J]. Journal of PLA University of Foreign Languages, 2016, 39(01):96-103+159.

[29] Qu \& Deng. A study on the corpus-based acquisition model of lexical chunks [J]. Foreign Language World, 2010(01):47-53.

[30] Shi. Formulaic sequences: its syllabus design and teaching implications [J]. Journal of Course Materials and Teaching Methods, 2014, 34(02):88-93.

[31] Yu. An experimental study on improving students' practical English competence by the lexical approach [J]. Foreign Language World, 2008(03):54-61.

[32] Zhang. The effect of cognitive style and glossing on the incidental acquisition of EFL formulaic sequences [J]. Foreign Languages in China, 2018, 15(04):77-84.

[33] Zhang et al. EFL collection research: a state-of-art review [J] Modern Foreign Languages, 2020, 44(1):123-132.

[34] Zhao. The Influence of recitation on the acquisition of English chunks [J]. Foreign Language Learning Theory and Practice, 2008(02):45-49.

[35] Zhou. Frequency effects on the acquisition of formulaic sequences: a corpus-based account [J]. Foreign Languages and Their Teaching, 2014(06):62-67. 